\title{
Design and Simulation of an Ozone Catalytic Oxidation System Based on Programmable Logic Controller
}

\author{
Rui Wang*, Jiaqi Li, Xianbin Gao, Yihao Dong \\ School of Chemistry \& Chemical Engineering, Yan'an University, Yan'an 716000, China
}

Corresponding Author Email: wangrui573832724@126.com

https://doi.org/10.18280/jesa.530410

Received: 21 April 2020

Accepted: 5 July 2020

\section{Keywords:}

ozone catalytic oxidation (OCO), industrial wastewater, programmable logic controller $(P L C)$, potential of hydrogen $(\mathrm{pH})$ control, simulation

\section{INTRODUCTION}

In recent years, the rapid industrial development has brought various environmental problems, the most serious of which is water pollution. For example, the oily wastewater discharged by the chemical industry becomes a major bottleneck in the sustainable development of chemical enterprises. Most wastewater treatment projects adopt traditional methods like biochemical treatment and physical settlement. But the treated water is poorly biodegradable, containing lots of refractory organics and salts [1]. Against this backdrop, ozone catalytic oxidation (OCO) has attracted much attention as a novel wastewater treatment technology. It is the most widely used and fastest growing advanced oxidation method [2].

Focusing on the production of new catalysts, foreign research on OCO mainly improves the catalytic effect by changing the composition, shape, and performance of the original catalyst [3]. For example, Quiñones et al. [4] created a new catalyst by loading titanium dioxide on magnetic activated carbon, which can basically remove microsomal triglyceride transfer protein (MTP) in $2 \mathrm{~h}$ and mineralize the MTP within 5h. By impregnation and sol-gel method, Hu et al. [5] loaded copper oxide on the aerogel carbon support, and proved that the catalyst thus prepared can improve the degradation rate of organics to $46 \%$ after $1 \mathrm{~h}$ reaction in a semicontinuous reactor.

Focusing on the technical aspect, domestic research on OCO mainly optimizes the overall effect of catalytic oxidation by improving some reaction conditions or combining OCO with other technologies. For instance, Mi et al. [6] integrated OCO technology with engineered microbe - biological aerated filter (EM-BAF) to lower the mean chemical oxygen demand (COD) of the treated water to $35.6 \mathrm{mg} / \mathrm{L}$, and that of the reverse osmosis (RO) concentrate to $33.1 \mathrm{mg} / \mathrm{L}$; this hybrid strategy manages to reduce the chroma and COD index, while improving the biodegradability of water.

Despite the considerable progress in catalyst preparation and technology, there is little report on the control of OCO system. To make up for the gap, this paper attempts to design and simulate an OCO system with programmable logic controller (PLC). The main idea is to regulate the entire treatment system and the potential of hydrogen $(\mathrm{pH})$ in the reaction with proportional-integral-derivative (PID) control, improving the automation and reducing the operating risks of wastewater treatment. To make the reaction more efficient, the $\mathrm{pH}$ was subject to PID control through the reaction. The proposed OCO system was simulated on Kingview software. The research results provide a theoretical reference for OCO control in industrial processes.

\section{PREPARATIONS}

\subsection{Influencing factors of reaction}

The recent research on OCO has been focusing on efficiency improvement and cost reduction. In this context, it is of great significance to analyze the factors affecting the reaction. Chen et al. [7] investigated the OCO of the water discharged by a wastewater treatment plant in an industrial park of Yancheng, eastern China's Jiangsu Province, and discovered that the OCO efficiency is affected by seven factors, including catalyst type, gas flowrate, catalyst dosage, catalyst particle diameter, residence time, $\mathrm{pH}$, and water temperature. The first five factors can be manually controlled, while $\mathrm{pH}$ and water temperature are difficult to regulate. The last two factors play a vital role in water treatment process. Therefore, this paper emphasizes on the effects of $\mathrm{pH}$ and water temperature on the reaction. 


\subsection{Effects of pH on OCO}

It is generally believed that, when the $\mathrm{pH}$ is low, the watersoluble ozone molecule is the oxidant in the OCO test. With the growing $\mathrm{pH}$, the wastewater treatment effect continues to improve. However, the positive effect of $\mathrm{pH}$ on OCO will be weakened if the $\mathrm{pH}$ surpasses a certain threshold [8]. Hence, the optimal OCO effect can be achieved in a slightly alkaline environment.

\subsection{Effects of water temperature on OCO}

Zhen et al. [9] have shown that water temperature does not have a significant effect on the removal of organics. Initially, the organic removal rate increases with the temperature. But when the water temperature exceed $35^{\circ} \mathrm{C}$, the removal rate will enter a decline. This means the treatment effect of OCO on industrial wastewater will worsen, after the water temperature reaches a certain threshold. The most suitable range of water temperature is $25-35^{\circ} \mathrm{C}$. Based on actual conditions, $25^{\circ} \mathrm{C}$ was selected as the best water temperature for OCO.

When the other conditions remain the same, the $\mathrm{pH}$ plays a more decisive role in the OCO process than water temperature.

\section{SYSTEM DESIGN}

As shown in Figure 1, the OCO system mainly consists of a physical sedimentation unit, an ozone generating unit, a reaction system, and an exhaust destruction system [10].

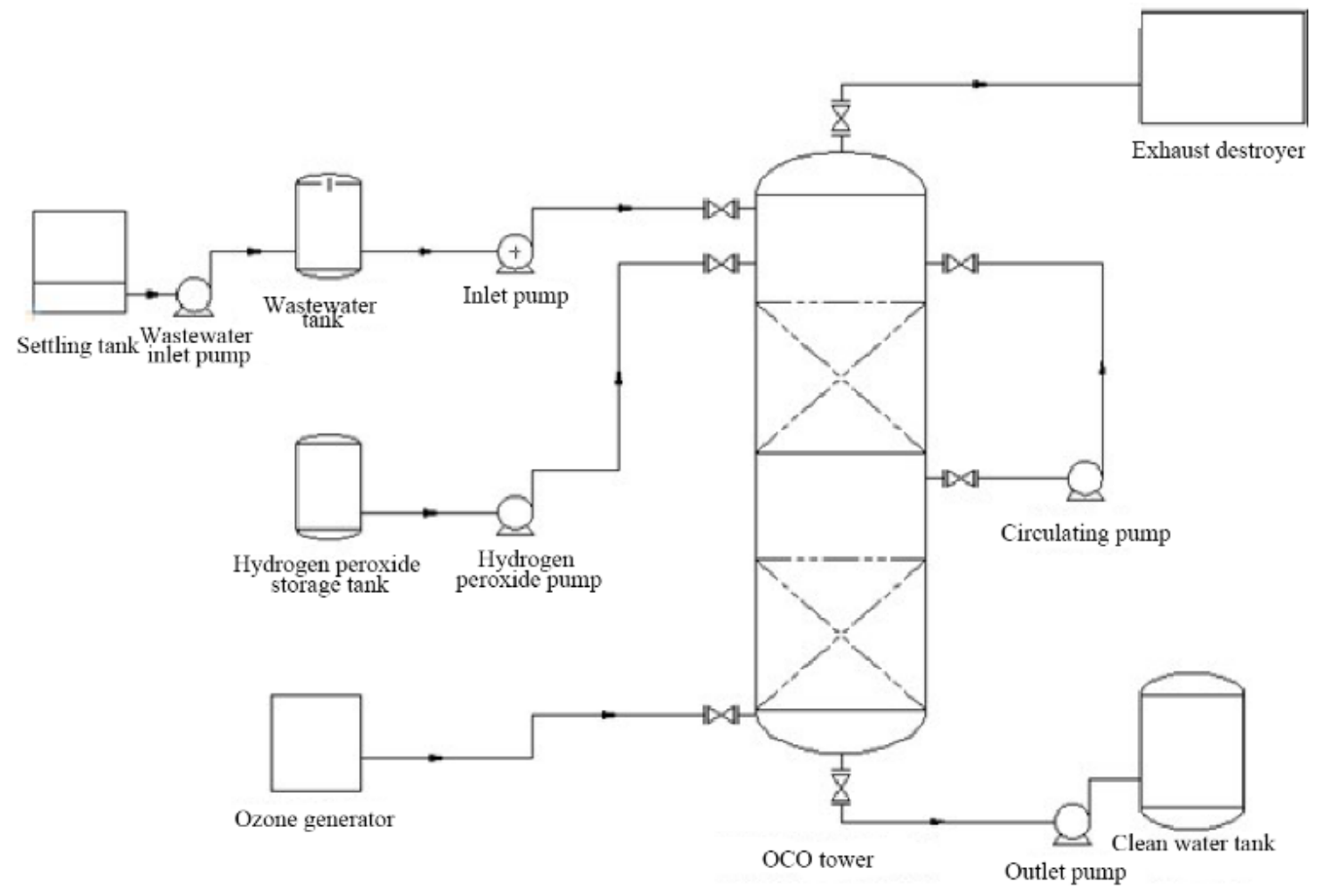

Figure 1. The OCO system

\section{$3.1 \mathrm{pH}$ control}

During wastewater treatment, the $\mathrm{pH}$ needs to be stabilized at around 9. In this case, the titration curve of the neutralization reaction is highly linear, and the PID control can meet the requirement [11]. Here, the titration image is divided into three parts (i.e. 0-4.70, 4.70-9.60, and 9.60-14) with different magnification coefficients. Then, three-stage nonlinear PID control was introduced to control the $\mathrm{pH}$ of the three parts [12]. Figure 2 shows the principle of a typical PID controller.

As shown in Figure 2, the PID controller takes proportional, integral, and derivative actions, according to the system error. In conventional PID control, there is a fixed amplification factor. If the factor is too large, the system accuracy and overshoot will increase, but the system oscillation will intensify, making system control more difficulty. If the factor is too small, the system response will slow down and system accuracy will drop; the decline in control effect cannot meet production requirement [13].
Therefore, the change range of $\mathrm{pH}$ was divided into three parts. A relatively large amplification factor was adopted for the low $\mathrm{pH}$ part, and a relatively small factor for the high $\mathrm{pH}$ part.

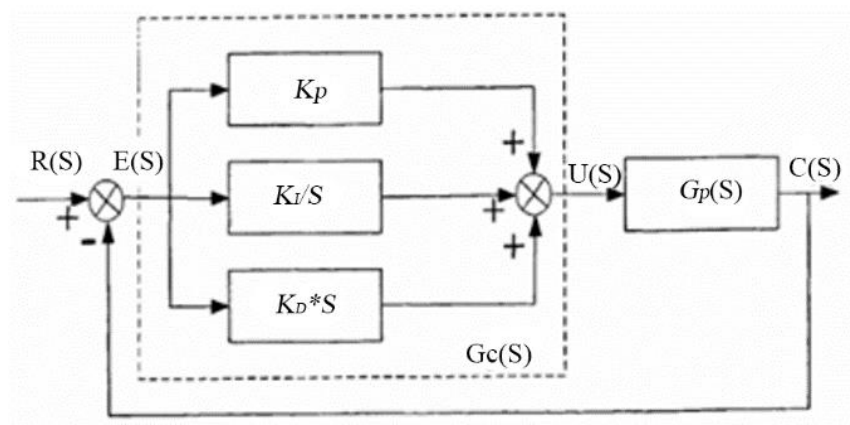

Figure 2. The principle of a typical PID controller 
Because the reaction must be maintained in an alkaline state, hydrogen peroxide was directly applied to adjust the $\mathrm{pH}$ of the system. When the $\mathrm{pH}$ deviates from the equilibrium state, the amount of hydrogen entering the system was changed by adjusting the opening of the hydrogen peroxide pump until the system $\mathrm{pH}$ is as required.

\subsection{Signal transmission and processing of $\mathrm{pH}$ control system}

To control the $\mathrm{pH}$ through the reaction, a single closed loop control system was constructed to make a timely feedback upon detecting a signal. Then, the reaction system can adjust the $\mathrm{pH}$ based on the feedback. The $\mathrm{pH}$ control system includes three parts: signal collection and transmission, signal calculation and processing, and signal output.

The $\mathrm{pH}$ control system needs to reflect the features of $\mathrm{pH}$, collect and transmit $\mathrm{pH}$ values, and make fast and timely control of $\mathrm{pH}$. To monitor the real-time $\mathrm{pH}$ of the reaction, the probe of the sensor was directly contacted with the reaction liquid. Any change to the $\mathrm{pH}$ of the liquid will induce a change in the potential of the sensor, creating a potential difference. The signal is transmitted via the wire to a $\mathrm{pH}$ meter, and converted into an electrical signal.

The transmission of $\mathrm{pH}$ value results in a current between 4-20mA. The current signal must be further processed to control the pump. Therefore, the current signal was imported to an analog/digital (A/D) converter. The resulting digital signal will be transmitted to the single-chip microcomputer (SCM). Then, the digital signal sent out by the SCM will be converted into a 4-20mA current signal by a digital/analog (D/A) converter. Finally, the current signal will act on the hydrogen peroxide pump, directing it to change its opening. In this way, the dosage of hydrogen peroxide is adjusted, which in turn regulates the $\mathrm{pH}$ in the reaction liquid.

Whereas the SCM is extremely complicated to design, PLC controllers can be developed quickly and reliably [14]. Hence, a Siemens S7-200 PLC controller was selected as the processor of our $\mathrm{pH}$ control system.

\subsection{Lower computer system}

The lower computer was designed by the PLC program to realize the monitoring of actuators and sensors. The main functions of the lower computer are to acquire the system states and feed back them to the upper computer, including $\mathrm{pH}$, oxidation reduction potential (ORP), as well as the speed and on-off state of each pump. The hardware of the lower computer consists of displays, sensors, signal lights, pumps, electrical control cabinet, PLC controller, and expansion modules. The control diagram of the electrical system is shown in Figure 3.

The control process is as follows: Once the switch is turned on, the whole system will begin to run, and the PLC controller will send a signal to the signal light to indicate the on-off state of the system. Then, all sensors will start to work. The ORP sensor will transmit its signal to the ORP display to show the potential. The ORP will be converted into a linear quantity and sent to the PLC controller. Similarly, the $\mathrm{pH}$ displays receive the signal from the $\mathrm{pH}$ sensor and shows the $\mathrm{pH}$ value of the system. Then, the $\mathrm{pH}$ value will be converted before being sent to the PLC controller. The voltage converter converts the voltage from $220 \mathrm{~V}$ to $5 \mathrm{~V}$ for pump control. Finally, the PLC controller issues signals to control the pumps and ozone generator, referring to the received signals.

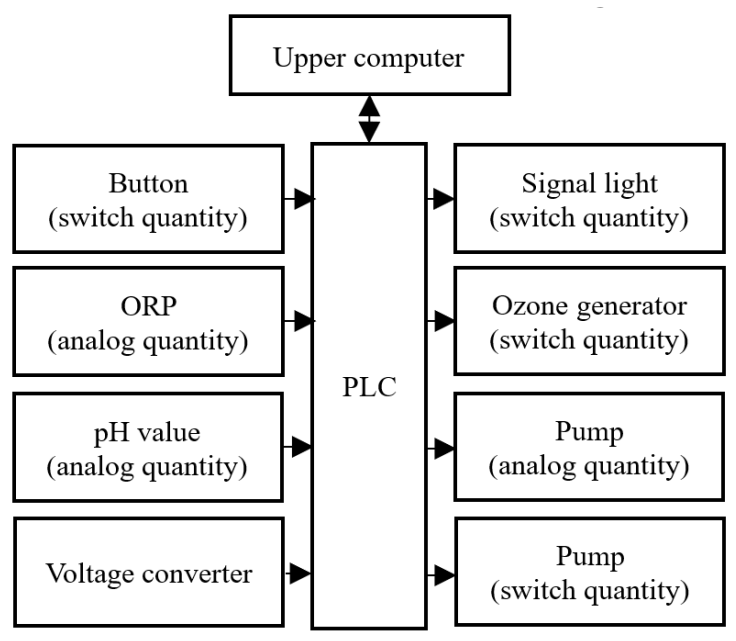

Figure 3. The control diagram of the electrical system

\subsection{Input/output (I/O) resources}

For the control system, the analog inputs include the input signals of sensors; the analog outputs include pump speeds, regulated flow, etc.; the digital inputs include the automatic control, manual control, and stop commands, as well as switch signals; the digital outputs are used to turn on or off signal lights, ozone generator, and pumps.

\subsection{Other accessories}

\section{(1) $\mathrm{pH}$ meter}

Our system selects an SIN-pH4.0 industrial pH meter. In actual process, the output current of the $\mathrm{pH}$ sensor is not linearly correlated with $\mathrm{pH}$. Therefore, the output current was imported to the $\mathrm{pH}$ meter for conversion, before being transmitted to the PLC controller.

Although the PLC controller supports RS485 communication, the specific transmission program was compiled in the PLC programming software, in addition to the connection of optical cable. For the lack of space, the ladder diagram of the program is not displayed.

(2) ORP meter

Our system selects an SIN-pH4.0 industrial ORP meter. Similar to the $\mathrm{pH}$, the output current of the ORP sensor is not linearly correlated with $\mathrm{pH}$. Therefore, the output current was converted by the ORP meter before being transmitted to the PLC controller.

\section{(3) 5 peristaltic pumps}

Our system adopts 5 WT600-2J Longer peristaltic pumps (Baoding, China). The pump heads are of the type YZ1515x. The flow rate of each pump falls in the range of 4.2$6,000 \mathrm{~mL} / \mathrm{min}$. The pumps can be controlled by various modes, e.g. manual control and external interface control.

(4) Ozone generator

Our system adopts a 3S-H integrated freeze-drying oxygen and ozone generator. Through intelligent technology, the generator fully integrates the functions of air compressor, filter, dewaterer, freezing dryer, oxygen generator, and ozone generator

(5) Exhaust destroyer

Our system adopts a TPY-HMQ2759 ozone exhaust destroyer. 
After the hardware design, the control program was compiled on STEP 7 MicroWIN V4.0 S7-200.

\subsection{Main program}

The control program of S7-200 PLC controller is composed of a main program, subprograms, and interrupt program [15]. As the core program, the main program needs to be executed after the completion of each scan cycle. The subprograms can be called by the main program. The design idea of the main program is introduced below:

(1) If the system is set to the manual mode, the green light will turn on at the first operation. At this time, the wastewater inlet pump pumps the wastewater into the settling tank, and the PLC timer starts counting for $15 \mathrm{~min}$. Once the tank is full, the wastewater inlet pump and the hydrogen peroxide pump will be turned on to inject the wastewater and $70-400 \mathrm{mg} / \mathrm{L}$ hydrogen peroxide into the OCO tower, and the PLC timer will starts counting for $15 \mathrm{mins}$. When the reaction liquid reaches the level limit of the tower, the wastewater inlet pump will be closed. Meanwhile, the ozone generator and the circulating pump will start to work, and the PLC timer will start counting for $1 \mathrm{~h}$. During the reaction, the $\mathrm{pH}$ of the reaction liquid can be regulated by adjusting the opening of the hydrogen peroxide pump. Finally, the outlet pump will be turned on to discharge the wastewater.

(2) If the system is set to the automatic mode, the red light will turn $\mathrm{n}$, and the timer will start counting for 30min. During this period, the manual mode was adopted to prevent the system from making large errors. After 30min, the PID program will be started to control the hydrogen peroxide pump, and monitor whether the $\mathrm{pH}$ of the reaction liquid reaches the set point.

(3) If the system encounters a secondary operation (i.e. restarts after stopping), all parts must be filled with liquid. In this case, there is no need to leave too much time for the pumping of wastewater. The secondary operation can be identified by detecting whether there is solution in the wastewater tank for a period. If it is a secondary operation, the timer will start to count for $15 \mathrm{~min}$ to keep the operations of all devices in sync, and the wastewater pumping will be completed in this period. In manual mode, the system starts to run when the green light is on and all devices are turned on. In automatic mode, the PID control phase will begin when the red light is on and all devices are turned on

(4) The stop button can send a signal to request the system to shut down.

\subsection{PID pH control system}

The workflow of the PID pH control system is explained in Figure 4.

As shown in Figure 1, if the signal is 1 , the system will enter the manual mode, and the speed of the hydrogen peroxide pump will be controlled by the analog output; if the signal is 0 , the system will enter the automatic mode, and the speed of the hydrogen peroxide pump will be adjusted automatically.

The first step of PID controller design is to determine its parameters. The parameters cannot be configured directly on the main program. Instead, a subprogram should be designed, and then called by the main program [16]. After the subprogram page was established, the $\mathrm{pH}$ subprogram can be configured by clicking the PID function key in the wizard option of the option bar. During the setting, the input interface of PID loop parameters will appear (Figure 5). The relevant parameters can be configured on this interface.

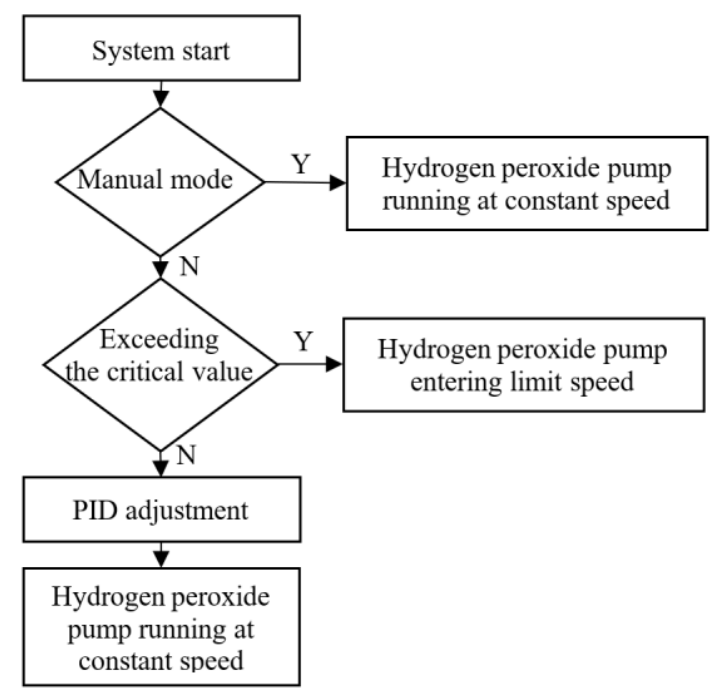

Figure 4. The workflow of the PID pH control system

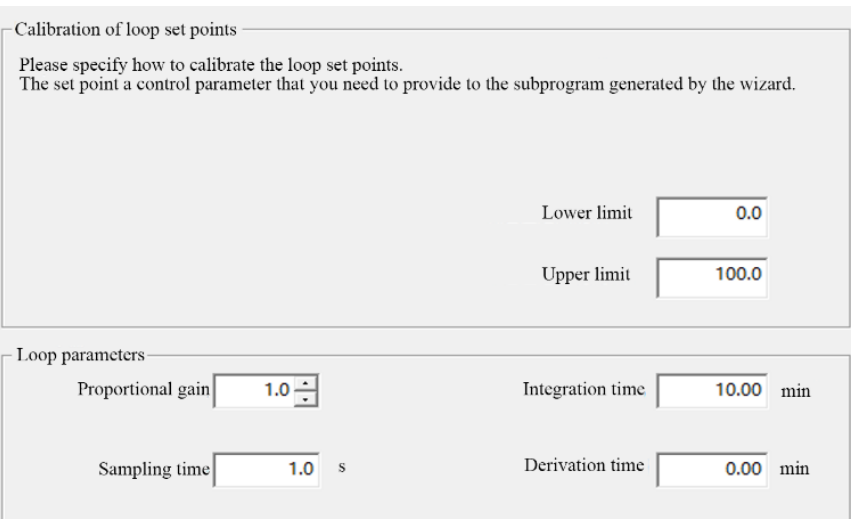

Figure 5. The setting of PID loop parameters

After setting all PID parameters, the function box of calling the initial state of the wizard PID program can be obtained. The program is stored in the subprogram PID EXE, which will be called periodically by the PLC controller.

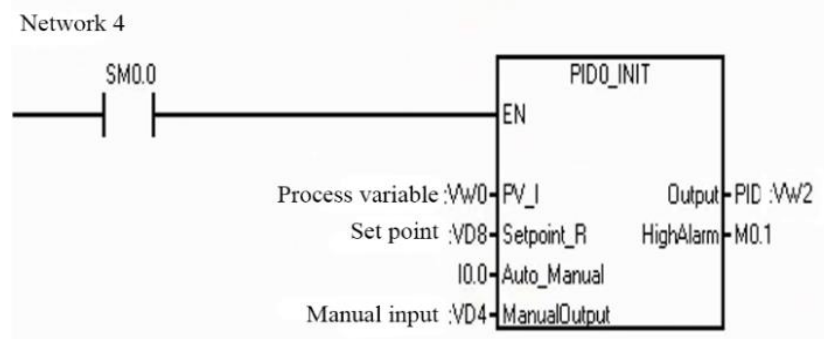

Figure 6. The initial state of PID subprogram

The next step is to define the control object. As shown in Figure 6, I0.0 in the subprogram is the button to switch between the manual mode and automatic mode of the PID program. If I0.0 is ON, the system is in automatic mode; if it is OFF, the system is in manual mode.

The process variable PV of the control object will be transmitted to the controller, and taken as the input VW0 of the controller. Then, VW0 and the set point will be calculated, 
producing an output VW2. The output will be transmitted to the control variable, causing the latter to change.

After the PID subprogram and object subprogram are ready, the system can run as required by directly calling the subprograms in the main program.

\section{SIMULATION}

The upper computer of the OCO automatic monitoring system is a human-computer interaction (HCI) platform, which provides an operating platform for engineers and operators. The upper computer is an Advantech industrial computer [17], and the control platform was designed on Kingview 6.60. The software is a development tool for monitoring systems. It is good at simulating industrial automation systems [18]. Next, open the device wizard interface, and set up six new pages: monitoring screen, pump adjustment screen, $\mathrm{pH}$ control screen, liquid level adjustment screen, trend line screen, and exit screen. These pages form the upper computer page of the project (Figure 7). These screen are saved in pic. format in the project folder.

Open the monitoring screen, find the gallery in the function bar, and click on the gallery. Then, the graphics of the relevant parts of the screen can be selected. The graphics of all devices needed for the monitoring screen, such as storage tank, OCO tower, pumps, switches, and pipes, are available in the gallery. Then, drag them to the corresponding positions for initial fusion.

Figure 8 presents the overall monitoring platform of our system. The monitoring platform can start and shutdown the system, display and switch between manual and automatic states, and display time and the circulation state of each pipe, etc. When the button is switched to manual, the green signal light is on; when the button is switched to automatic, the red signal light is one. When a pump is started, its signal light will turn red; when a pump is stopped, its signal light will turn red.

Each cycle of the OCO system goes as follows: First, the wastewater in the settling tank enters the wastewater tank under the action of the wastewater inlet pump, and then flows into the OCO tower. In the meantime, the ozone generator passes the generated ozone to the bottom of the tower, while the hydrogen peroxide is transported from the hydrogen peroxide storage tank to the top of the tower. The ozone and the hydrogen peroxide will react under the action of the catalyst. After a period of reaction, the outlet pump is turned on to drain the wastewater in the tower.

To switch between screens, a drop-down menu must be drawn on the page. First, find the menu in the toolbar, drag a menu area on the screen, double-click and the edit page that appears. In this way, a new subitem can be created as Figure 9.

After setting the main elements of the screen, it is necessary to associate all variables. On the project browser, customize three variables in the variable module: the level of wastewater tank, the level of hydrogen peroxide tank, and the level of the clean water tank. Set the variable type as I/O real number, and the connected device as simulation. In addition, adjust the maximum and minimum values, and the reading frequency of each variable.

After the variable setting, return to the monitoring platform page of the development system, double-click each storage tank, and associate the relevant variables. Create new variables for each pump, and associate each pipe with each pump. The pipe can only be connected when the pump is green. A pipe is connected when its flow state turns from black to green. Furthermore, associate the switch of each pump with the total switch. Figure 10 provides a screenshot of the monitoring system during the operation of the OCO system.

\begin{tabular}{|c|c|}
\hline Name of screen & File \\
\hline Pump adjustment & pic00002.pic \\
\hline 原 $\mathrm{pH}$ control & pic00003.pic \\
\hline 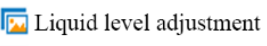 & pic00004.pic \\
\hline 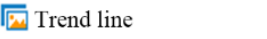 & pic00005.pic \\
\hline 原 Exit & pic00006.pic \\
\hline 原 Monitoring screen & pic00007.pic \\
\hline 原 Create new screen & pic00001.pic \\
\hline
\end{tabular}

Figure 7. The new screens

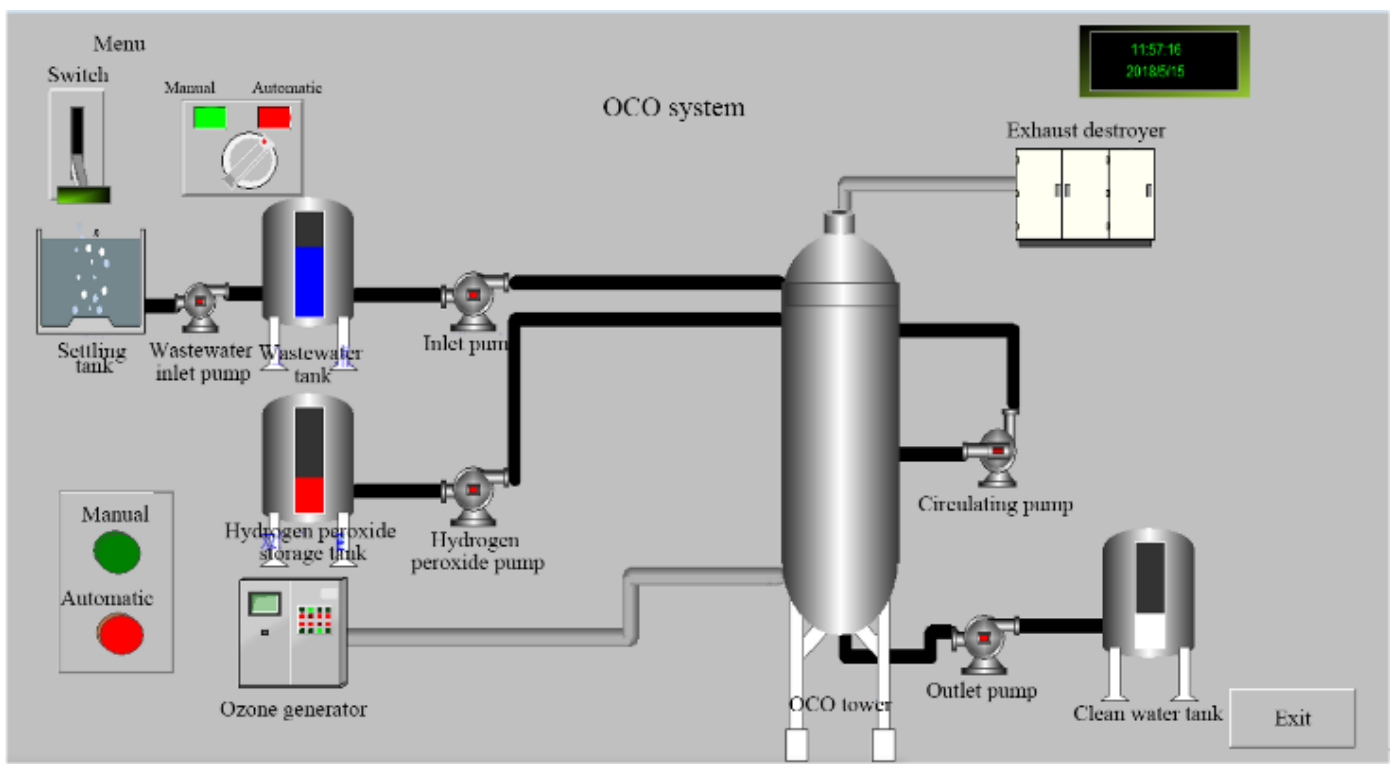

Figure 8. The monitoring screen of the OCO system 
After the design of the automatic control interface, the other screens of the OCO system should be created in turn. First, open the layer where the trend curve is located, and enter the text of trend curve at the center of the page. The main components on this page are real-time curves and historical curves.

Take the real-time curves as an example, find the real-time curve button in the toolbox, and create a real-time curve on the screen. Then, double-click the real-time curve to display the editing screen, associate the curve with related variables, and click the corresponding curve color, such that the three variables are in three different colors. Finally, click OK to finish editing.

After editing, mark the variable represented by each curve in the form of text, and create a new text next to the variable for the output of the analog value. In this way, the value of the variable can be read directly through the new text whenever the variable changes.

The historical curves can be plotted in a similar way. The only difference is that the variables associated with historical curves need to be stored in the history during variable setting. Hence, remember to check the required variables before variable setting.

Figure 11 shows the trend curve page of the level of wastewater tank, the level of hydrogen peroxide tank, and the level of the clean water tank. The real-time and historical curves of the three levels are displayed simultaneously on the page. Thus, the operator can observe, record, and adjust the specific levels in the three tanks.

Figure 12 shows the design of the pump adjustment page, which includes the wastewater inlet pump, hydrogen peroxide pump, circulating pump, and outlet pump. The main function of this page is to control and record the opening of each pump.
On this page, the operator can turn on/off the pump, switch the pump between manual and automatic modes, and input a specific value to the pump. The system can be changed by adjusting the opening of the pumps.

Figure 13 displays the design of the $\mathrm{pH}$ control page. On this page, the dosage of hydrogen peroxide to the OCO tower can be adjusted by changing the opening of the hydrogen peroxide pump, which in turn affects the $\mathrm{pH}$ of the reaction liquid. This page can control of the hydrogen peroxide pump independently, including changing the dosage and switching the pump between manual and automatic modes. The page also presents the $\mathrm{pH}$ curve of the reaction over time. Hence, the operator can obtain the real-time $\mathrm{pH}$ of the tower from this page.

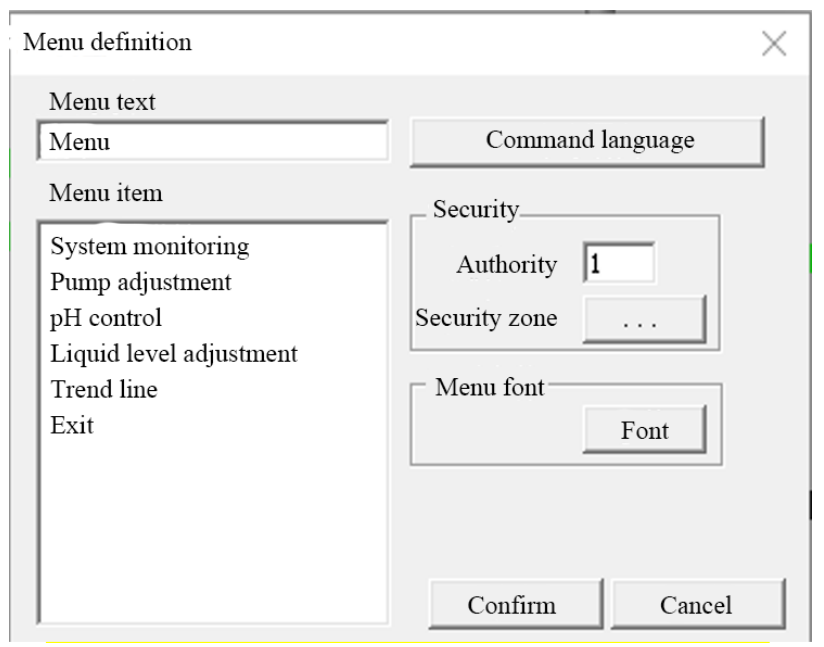

Figure 9. The menu definition screen

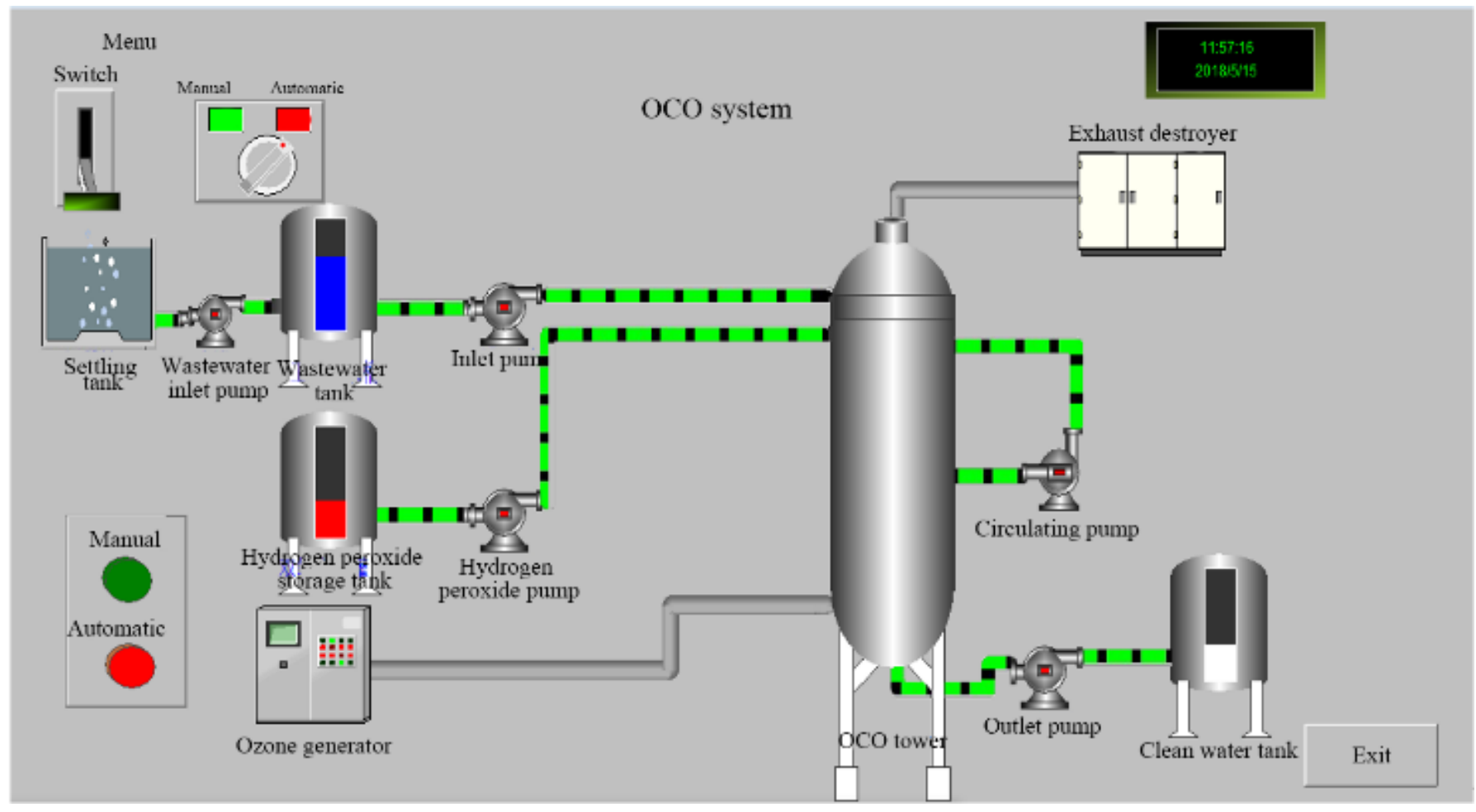

Figure 10. A screenshot of monitoring system 


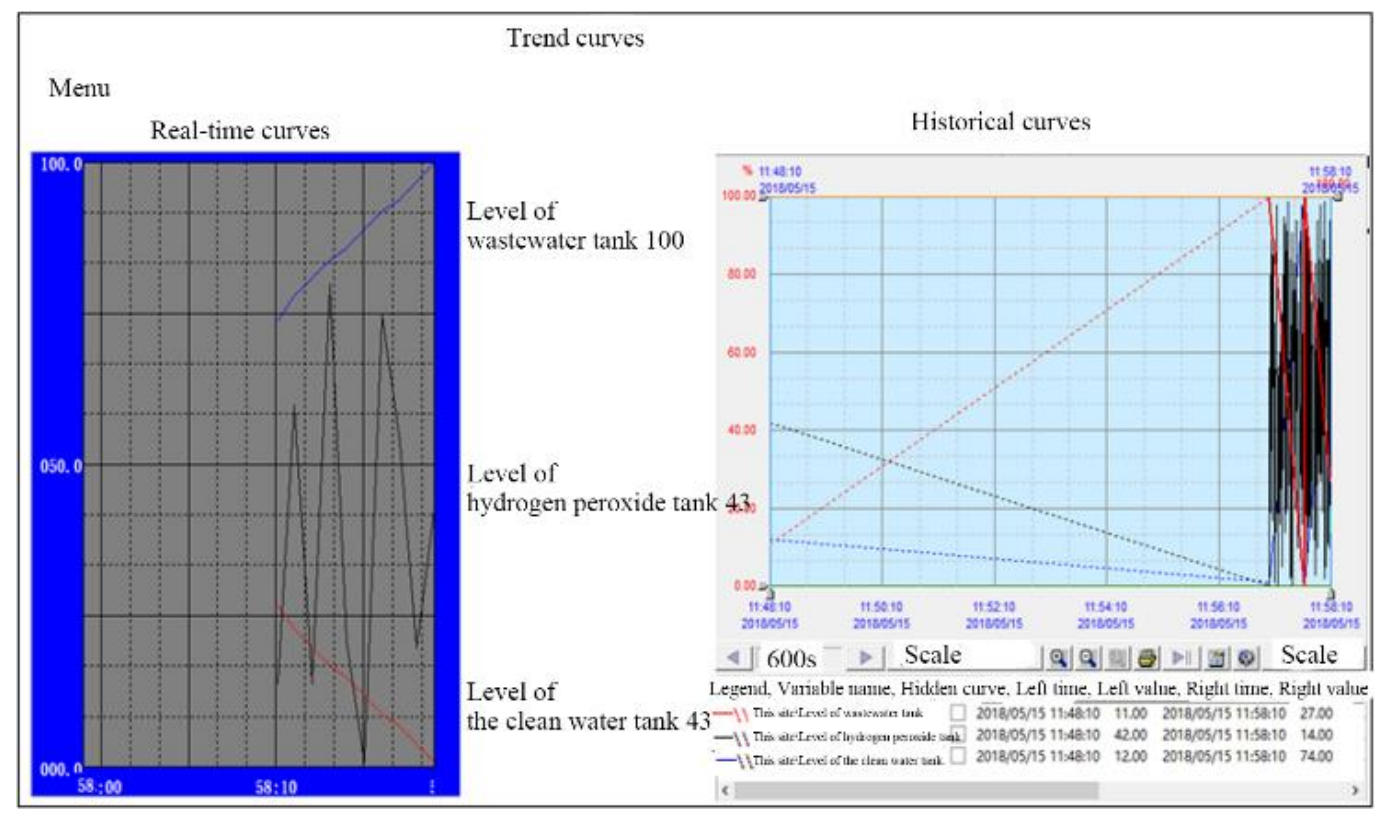

Figure 11. The trend line page

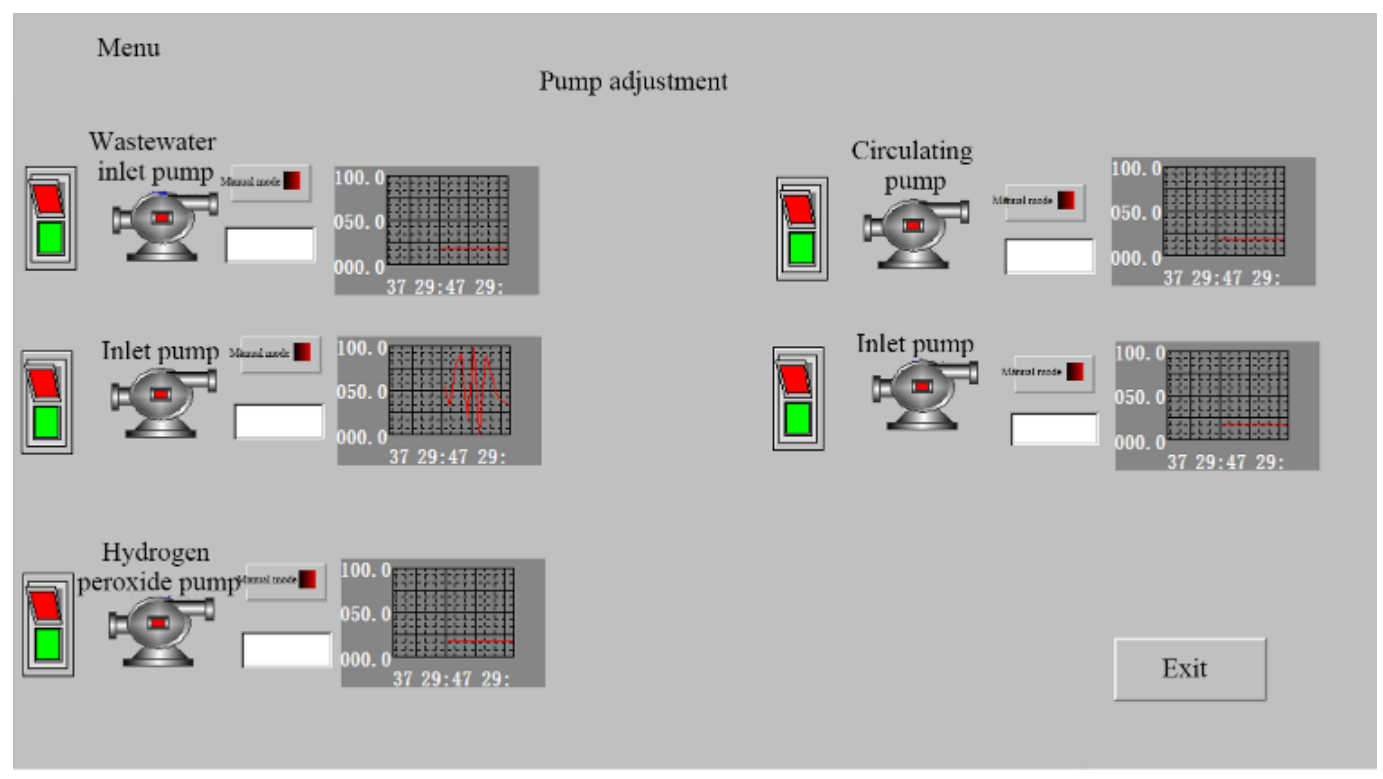

Figure 12. The pump adjustment page

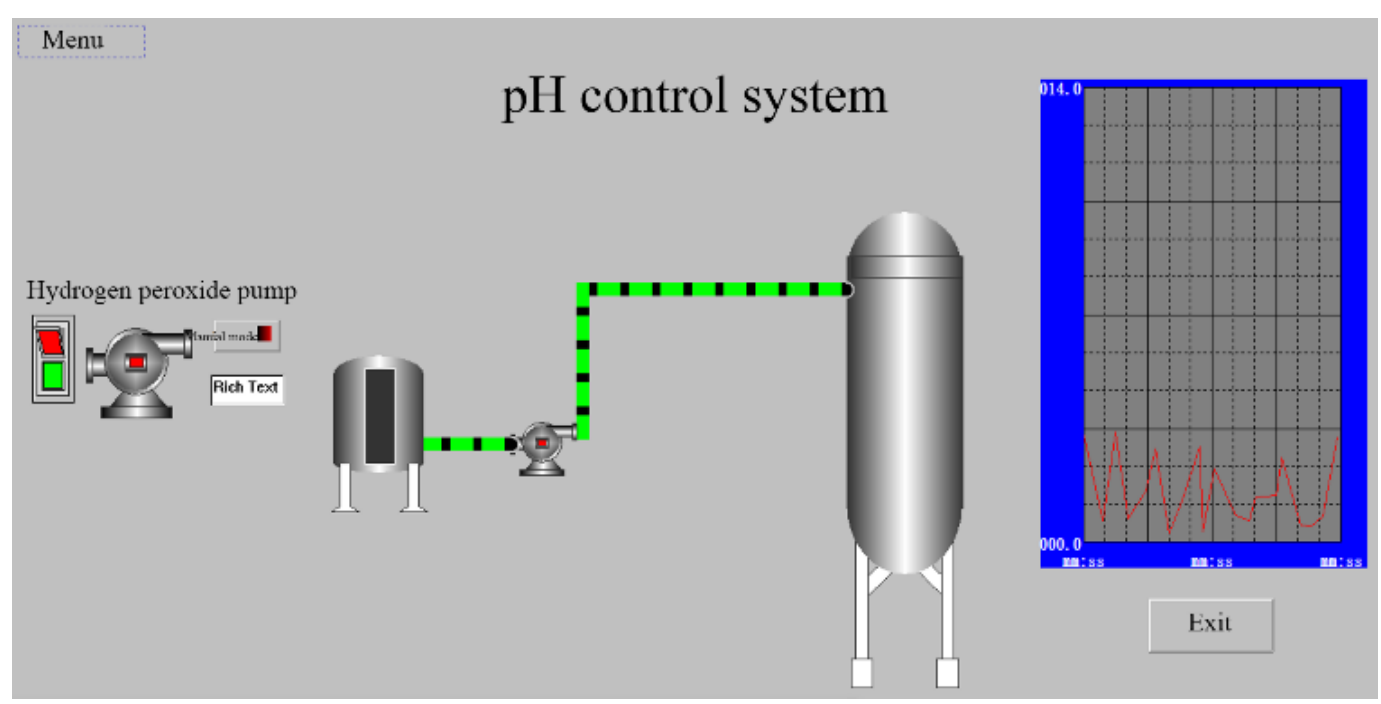

Figure 13. The $\mathrm{pH}$ control system page 


\section{CONCLUSIONS}

This paper designs and simulates an OCO system based on the PLC. There are two main innovation points: The first lies in the control of the $\mathrm{pH}$ of the system. Based on the original system, a segmented PID control method was adopted to regulate the $\mathrm{pH}$ value, making the reaction more efficient and complete. The other innovation is to solve the low automation and complex control of OCO through PLC programming and Kingview simulation. Our method promotes the development of OCO technology, and provides a new solution for the treatment of industrial wastewater. Apart from of industrial wastewater treatment, the designed OCO system boasts broad prospects and a high market value in disinfection, wastewater treatment, and deodorization.

\section{ACKNOWLEDGMENT}

This work was supported by Teaching Reform Research Project of Yan'an University (Grant No.: YDJG2016-15), Classroom Teaching Reform Project of Yan'an University (Grant No.: KTJG2017-75), and School-Level Scientific Research Planning Project of Yan'an University (Grant No.: YDQ2019-23).

\section{REFERENCES}

[1] Rodrigues, A.C., Boroski, M., Shimada, N.S., Garcia, J.C., Nozaki, J., Hioka, N. (2008). Treatment of paper pulp and paper mill wastewater by coagulationflocculation followed by heterogeneous photocatalysis. Journal of Photochemistry and Photobiology A: Chemistry, 194(1): 1-10 https://doi.org/10.1016/j.jphotochem.2007.07.007

[2] Ye, X. (2018). Application of ozone oxidation technology in wastewater treatment. Shandong Industrial Technology, 3(2): 42-30 https://doi.org/10.16640/j.cnki.37-1222/t.2018.03.036

[3] Li, W.M., Bai, Y.G., Zhou, J., Cao, L. (2019). Selection and design of catalytic ozonation in wastewater advanced treatment of industrial park. Water \& Wastewater Engineering, 45(5): 90-93. https://doi.org/10.13789/j.cnki.wwe1964.2019.05.016

[4] Quiñones, D.H., Rey, A., Álvarez, P.M., Beltrán, F.J., Plucinski, P.K. (2014). Enhanced activity and reusability of $\mathrm{TiO}_{2}$ loaded magnetic activated carbon for solar photocatalytic ozonation. Applied Catalysis B: Environmental, 144: 96-106. https://doi.org/10.1016/j.apcatb.2013.07.005

[5] Hu, E., Wu, X., Shang, S., Tao, X.M., Jiang, S.X., Gan, L. (2016). Catalytic ozonation of simulated textile dyeing wastewater using mesoporous carbon aerogel supported copper oxide catalyst. Journal of Cleaner Production, 112: 4710-4718. https://doi.org/10.1016/j.jclepro.2015.06.127

[6] Mi, Z.Y., Duan, S.L., Yu, Y.P., Zhao, C.M. (2018). Application of catalytic ozonation and EM-BAF technology in wastewater treatment. Refining and
Chemical Industry, 29(1): 67-69.

https://doi.org/10.16049/j.cnki.lyyhg.2018.01.023

[7] Chen, L., Xu, Y., Sun, Y. (2019). Combination of coagulation and ozone catalytic oxidation for pretreating coking wastewater. International Journal of Environmental Research and Public Health, 16(10): 1705 https://doi.org/10.3390/ijerph16101705

[8] Wei, C.H., Zhu, J.L., Wu, C.F., Wu, H.Z., Lu, B., Li, G.B., Chen, J.G. (2011). Influence factors of coking wastewater components and pollution control. Chemical Industry and Engineering Progress, 30(1): 225-232. https://doi.org/10.16085/j.issn.1000-6613.2011.01.017

[9] Zhen, J., Mao, Y., Ning, L., Cheng, X.L. (2011). Degradation and transformation of organics in biochemicaly pretreated coking wastewater by ozonation. China Water \& Wastewater, 27(21): 72-75. https://doi.org/10.19853/j.zgjsps.10004602.2011.21.021

[10] Pachauri, N., Rani, A., Singh, V. (2017). Bioreactor temperature control using modified fractional order IMC-PID for ethanol production. Chemical Engineering Research and Design, 122: 97-112. https://doi.org/10.1016/j.cherd.2017.03.031

[11] Kang, Y.L., Zhang, X.B. (2015). Application of pH value control system in waste water treatment of coking. Hebei Metallurgy, $\quad$ (6): $\quad 78-79, \quad 82$. https://doi.org/10.13630/j.cnki.13-1172.2015.0621

[12] Xie, S.H., Gao, X.X., Li, L.T., Chen, J., Men, Y.J. (2014). Fuzzy immune PID control of $\mathrm{pH}$ value in chemical industry process. Computer Measurement \& Control, (1): 76-78. https://doi.org/10.16526/j.cnki.114762/tp.2014.01.080

[13] AlSabbah, S., AlDhaifallah, M., Al-Jarrah, M. (2015). Design of multiregional supervisory fuzzy PID control of $\mathrm{pH}$ reactors. Journal of Control Science and Engineering, 396879. https://doi.org/10.1155/2015/396879

[14] Zhu, H.J., Qiu, X.L. (2017). The application of PLC in sewage treatment. Journal of Water Resource and Protection, 9: 841-850. https://doi.org/10.4236/jwarp.2017.97056

[15] Wang, R., Zheng, W.G. (2013). The design of household automatic control water supply system based on PLC. In Advanced Materials Research, 706-708: 1099-1102. https://doi.org/10.4028/www.scientific.net/AMR.706708.1099

[16] Dang, J., Yuan, K., Shi, J., Huang, H., Wang, L. (2019). Monitoring system design based on kingview sewage treatment. Journal of Scientific Research and Reports, 111. https://doi.org/10.9734/jsrr/2019/v23i330123

[17] Ayala, H.V.H., dos Santos Coelho, L. (2012). Tuning of PID controller based on a multiobjective genetic algorithm applied to a robotic manipulator. Expert Systems with Applications, 39(10): 8968-8974. https://doi.org/10.1016/j.eswa.2012.02.027

[18] Du, Z.B. (2014). Study on treatment of wastewater system based on ARM. In Advanced Materials Research, 1006-1007: 732-735. https://doi.org/10.4028/www.scientific.net/AMR.10061007.732 